\title{
Short Communication: Digital identification approach to characterize Hevea brasiliensis leaves
}

\author{
BAYU PRATOMO ${ }^{1}$, LISNAWITA ${ }^{2}$, TENGKU CHAIRUN NISA ${ }^{2}$, MOHAMMAD BASYUNI ${ }^{3, \vartheta}$ \\ ${ }^{1}$ Doctoral Program of Agricultural Sciences, Faculty of Agriculture, Universitas Sumatera Utara. Jl. Prof. A. Sofyan No. 3, Medan 20155, North Sumatra, \\ Indonesia \\ ${ }^{2}$ Program of Agrotechnology, Faculty of Agriculture, Faculty of Agriculture, Universitas Sumatera Utara. Jl. Prof. A. Sofyan No. 3, Medan 20155, North \\ Sumatra, Indonesia \\ ${ }^{3}$ Department of Forestry, Faculty of Forestry, Universitas Sumatera Utara, Jl. Tri Dharma Ujung No. 1, Medan 20155, North Sumatra, Indonesia. \\ Tel./fax.: +62-61-820-1920. vemail: m.basyuni@usu.ac.id
}

Manuscript received: 15 December 2020. Revision accepted: 25 January 2021

\begin{abstract}
Pratomo B, Lisnawita, Nisa TC, Basyuni M. 2021. Short Communication: Digital identification approach to characterize Hevea brasiliensis leaves. Biodiversitas 22: 1006-1013. The purity of clones is a key factor to obtain uniform growth of Hevea brasiliensis Muell Arg in the field. Crop uniformity has an impact on production patterns that can be predicted in latex content. Basically, H. brasiliensis tree leaves show similarities to each other such as the color, texture, or shape of the leaves. Identification of clones that have been very common by the morphology of $H$. brasiliensis leaves. This study links the results of previous research on digital methods used. A total of 27 clones were sampled in this study which came from the garden collection of entres, which can be used as a source of elders for assisted pollination or source of planting materials for the needs of production-scale seeds in the field. Here, we used a database of 540 leaves from 27 clones and 10 quantitative characters to address these issues The analysis data used a randomized complete block design (RCBD) factorial. The result showed the identification method digitally on characterizing of leaves by using Software Adobe Photoshop, depicting that the characteristics contained in H. brasiliensis leaves are very proper to be used as the first character in identifying an $\mathrm{H}$. brasiliensis clone. The present work provided a piece of important information on the characterization of $H$. brasiliensis leaves to enhance the selection of parent clones.
\end{abstract}

Keywords: Characterize, clones, Hevea brasiliensis, identity, leaves

\section{INTRODUCTION}

The number of plant species or flora in Indonesia is abundant and their richness is unquestioned. Almost every region in Indonesia has one or more typical plants that may not exist in other countries. In increasing the potential diversity of tropical plant resources, good biodiversity management and utilization are required. Based on such diversity, the classification of plants becomes a challenge (Hidayat et al. 2018). In manual identification, special plant characteristics are determined as those that help in identifying the intended plant species. Conventional plant species identification methods (Kaur and Kaur 2019) seem impractical to ordinary people and are a challenge for professional taxonomy as well. Manual identification is often time-consuming and inefficient.

Since the traditional identification methods are strenuous, there arises a need to automate the process of species identification. Scientific and technological challenges in identifying species (Kolivand et al. 2018) or even subs below them such as varieties or clones of plants, against a wide variety of plants and countless taxonomic characteristics. The conditions of equatorial tropical forests have a high diversity of plants (Bruno et al. 2008), making traditional and very special taxonomic techniques difficult, slow, as most later manuals. Thus, researchers have tried to develop a system of identification and classification of plant species that can be used as a purpose of species recognition to some extent (Ghasab et al. 2015; Goyal and Kumar 2018).

In this digital era, smartphones and digital cameras are widely found and available to everyone. Digital images (Cerutti et al. 2013) have become an indispensable element of several fields, including facial recognition, plant recognition, and health informatics, computer vision (Valliammal and Geethalakshmi 2012). In addition, the development of technology (Bakhshipour and Jafari 2018) in the field of image processing and toolboxes available to implement it has aimed to automate the process of species identification. The most common way to recognize between one plant and another is to identify the leaves of each plant. Leaf-based classification is the most effective alternative and way to implement because the leaves will be there all the time, while fruits and flowers may only exist at any given time.

Nowadays the classification of plants is being carried out by computational models of leaf recognition systems. Most plant species have unique leaves that differ from each other based on characteristics such as shape, color, texture, and margin (Thibaut et al. 2011; Casanova et al. 2012). Databases for Hevea brasiliensis Muell Arg. tree species need to be set up to preserve the type of clones and as a source of elders for breeding programs. Introduction of plants through leaf shapes using image processing as initial 
processing inputted leaf images (Kaur and Kaur 2019) converted into binary images will then be further processed to find features (Wirdiani and Sudana 2016). Many methods can be used to calculate the extraction of features as well as the introduction of plants by identifying the shape (Agus et al. 2015, Pallavi and Devi 2014), segment (Lee and Hong 2013), color (Trishen et al. 2015), and leaf texture (Bhardwaj et al. 2013; Kadir et al. 2012).

Suhendry and Pasaribu (2009) studied the identification of $H$. brasiliensis clones through quantitative characteristics of $H$. brasiliensis leaves from several clones on some growth stadia. The purity of a clone plays a role in the uniformity of growth in the field on $H$. brasiliensis plantations. If the crop condition from various clones, it will produce a variety of $H$. brasiliensis planting growth. This present study aimed to evaluate the digital method to identify the characterization of the H. brasiliensis leaves a sample of the clones.

\section{MATERIALS AND METHODS}

\section{Plant materials}

The plant materials used as samples in this study came from the garden collection of PT Socfin Indonesia, Tanah Besih, Tebing Syahbandar, Serdang Bedagai Regency, North Sumatra Province, Indonesia. These sampling sites were located at $3^{\circ} 19.579^{\prime}$ north latitudes and $99^{\circ} 12.971^{\prime}$ east longitudes. The sample consisted of 27 clones of entres namely IRR 5, PB 217, PB 340, IRCA 18, IRCA 19, IRCA 41, IRCA 101, IRCA 130, IRCA 230, IRCA 317, IRVA 331, IRCA 427, IRCA 804, GT 1, IRR 220, IRR 221, IRR 429, IRR 440, PB 260, PC 10, PM 10, PR 300, RRIC 100, RRIM 901, RRIM 908, RRIM 921 and RRIM 2020. Each clone is taken as long as 20 strands of the middle leaf, from the trifoliate of $H$. brasiliensis leaves, considering the previous method described by (Suhendry and Pasaribu 2009; Pasaribu and Suhendry 2018) based on the variations between strands were not real, the size of the dominant middle leaf was larger than other leaf strands. Leaves that do not grow normally in shape and size, and disproportionately the breadth between each leaf in one stalk, are not used as a sample. The present study referred to the previous research that is distinguished using samples from a larger number of clones and repeated to validate obtained data for better and reliable results (Pasaribu and Suhendry 2018).

\section{Measurement techniques}

Each of the Sample leaves of 20 strands was randomly taken from 27 clones are planted on entres plantation. The abnormal leaves that have a disproportionate size and shape of strands were not selected as a sample. The middle leaf is separated from the stalk, given an identity number then the leaf is transferred into digital format through a scanner. With the help of Adobe Photoshop Software series 6, the leaves are cropped and measured the parameters of the marker. The scanned leaves are then manually extracted according to the same identity recorded on the computer.

In this research, the same activity was measured at several parameters. The three main quantitative characters used as parameters in this study are the size of the length, maximum leaf width, and angle on some parts of the leaves. Of the three main quantitative characters developed various sizes in Table 1 .

\section{Data analysis}

Data analysis to determine the influence of clones $(\mathrm{K})$, quantitative characters $(\mathrm{C})$, and interactions between $\mathrm{K}$ x C was conducted through a diversity analysis of RandomIzed Design Factorial Group (RCBD), where the number of leaves became a crosser. the following linear models are used in the analysis:

$$
Y_{i j k}=\mu+D_{k}+K_{i}+C_{j}+K_{i} C_{j}+E
$$

Note: Yijk was a response caused in the research unit that includes a combination of factors of the number of clones as much as I level and quantitative character as much as $\mathrm{j}$ level with a repeat in the form of the number of leaves as much ask level. $\mathrm{D}=$ leaf strand (repeat), $\mathrm{K}=$ number of clones, $\mathrm{C}=$ quantitative character, $\mathrm{KC}=$ interaction factor of clones and characters, and $\mathrm{E}=$ error.

Table 1. Various quantitative characters

\begin{tabular}{ll}
\hline Quantitative characters & Explanation \\
\hline Leaf length (P) & $\begin{array}{l}\text { It is measured by centimeter-scale from the lower end of the leaf (base) to the upper end of the } \\
\text { leaf (musty) } \\
\text { It is half the length of the leaf } \\
\text { Location of the leaf folding point is the bone length of the leaf from the point of the fold at the } \\
\text { maximum leaf width towards the musty }\end{array}$ \\
$\begin{array}{l}\text { Center point (TP) } \\
\text { It is measured by a centimeter-scale at the maximum leaf width }\end{array}$ \\
$\begin{array}{l}\text { Width of the leaf (L) } \\
\text { Widht of the left leaf strand of the measured at the maximum leaf width position from the left edge boundary of the leaf to the } \\
\text { vein (HKr) }\end{array}$ \\
$\begin{array}{l}\text { The angle of the natural base (B) } \\
\text { It is measured by using a bow at the bottom of the leaf following the border of the leaf edge with } \\
\text { the center point of the bow at the base of the stalk of the leaf strands }\end{array}$ \\
$\begin{array}{l}\text { The angle of the natural apex (A) } \\
\text { The angle of the vein (V) }\end{array}$ \\
$\begin{array}{l}\text { The angle of the vein against the leaf bone is the large angle between the veins against the leaf } \\
\text { bone measured in one of the veins that are around the folding point of the leaf }\end{array}$ \\
$\begin{array}{l}\text { It is an angle formed from the base of the stalk of the leaf strands to the outer side of the leaf at } \\
\text { the maximum leaf width }\end{array}$ \\
$\begin{array}{l}\text { It is an angle formed from the tip of the leaf strands to the outer side of the leaf at the maximum } \\
\text { leaf width }\end{array}$ \\
\hline
\end{tabular}



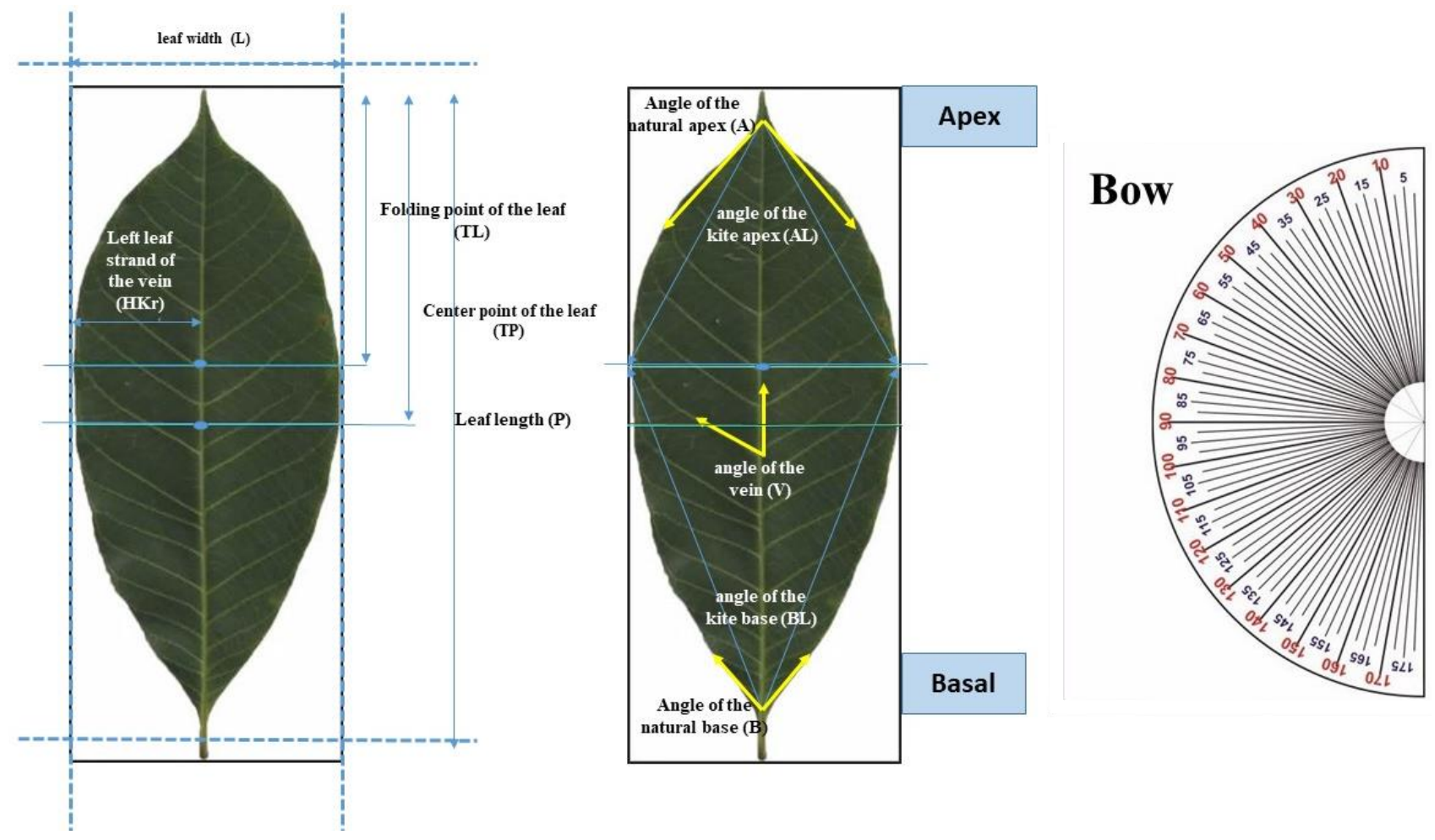

Figure 1. Points of measurement quantitative character of Hevea brasiliensis leaves

\section{RESULTS AND DISCUSSION}

\section{Results}

Table 1 shows the results of the analysis of variance from some factor, clones $(\mathrm{K})$, quantitative character (C). The R-Square value of 0.90 emphasized that the experimental model used the closer the number one will be the better. The coefficient variation of data analysis results is also in a good range with a value of 23.78 . Then based on probability results stated that both factor $\mathrm{K}$ and $\mathrm{C}$ and interaction both have a very real effect $(<.0001)$. This explains that 10 quantitative characters of $H$. brasiliensis leaves can be used for the identification of tested $H$. brasiliensis clones. Analysis data in Table 1 is processed from 27 clones with 10 quantitative characters and repeated
$3 x$, then there are 5400 data processed. Complete data on the average of quantitative characters of 27 clones were depicted in Table 2-5. The method of measurement displayed in Figure1 is illustrated with 10 different quantitative characters of the $H$. brasiliensis leaf.

Tabel 7 derived from the multiplication of length mean and width mean of leaves, as the main quantitative characters. Since the multiplication is not a rectangle, the term "approximate" is used. Table 6 described that RRIM 908 is the largest leaves (371.160) as mean and from all clones from table 2 until table 5 , as not identified clones type. Another type of slow starter represented by PB217 (312.732) and PB 340 (346.045) is the largest from quick starter clones.

Tabel 2. Analysis of variance (ANOVA) procedure

\begin{tabular}{llllll} 
Source & dF & SS & MS & FV & Pr $>$ F \\
\hline block & 19 & 1162.495 & 61.184 & 0.890 & 0.5971 \\
K & 26 & 20806.493 & 800.250 & 11.630 & $<.0001$ \\
C & 9 & 3062627.156 & 340291.906 & 4945.100 & $<.0001$ \\
K*C & 234 & 102845.018 & 439.509 & 6.390 & $<.0001$ \\
Error & 5111 & 351707.877 & 68.814 & & \\
Corrected Total & 5399 & 3539149.039 & & \\
R-Square & 0.90 & & & \\
Coefficient Variation & 23.78 & & & \\
\hline
\end{tabular}

Note: dF: the degree of freedom, SS: the sum of squares, MS: mean square, FV: F value, Pr: probability 
Tabel 3. Means of the quantitative character of Hevea brasiliensis leaves

\begin{tabular}{|c|c|c|c|c|c|c|c|}
\hline \multirow{3}{*}{ Quantitative character } & \multicolumn{7}{|c|}{ Clones of $\boldsymbol{H}$. brasiliensis plant from the entres collection plantation } \\
\hline & \multicolumn{6}{|c|}{ SS } & \multirow{2}{*}{$\begin{array}{c}\text { QS } \\
\text { IRCA } 18\end{array}$} \\
\hline & GT1 & IRCA 41 & PB 217 & PR 300 & RRIC 100 & RRIM 921 & \\
\hline Leaf length $(\mathrm{P})$ & 23.195 & 22.570 & 28.950 & 28.360 & 22.444 & 21.558 & 29.637 \\
\hline Leaf width (L) & 7.487 & 9.100 & 10.803 & 9.195 & 8.264 & 8.288 & 10.431 \\
\hline Left leaf strand of the vein $(\mathrm{HKr})$ & 3.741 & 4.562 & 5.404 & 4.807 & 4.335 & 4.414 & 5.236 \\
\hline Folding point of the leaf (TL) & 9.482 & 9.641 & 14.016 & 11.598 & 10.057 & 9.294 & 13.164 \\
\hline Center point of the leaf (TP) & 11.601 & 11.273 & 14.457 & 14.229 & 11.334 & 11.004 & 14.831 \\
\hline The angle of the natural base (B) & 57.136 & 68.870 & 82.150 & 50.562 & 74.208 & 56.060 & 68.472 \\
\hline The angle of the natural apex (A) & 61.455 & 80.930 & 63.580 & 63.324 & 74.396 & 79.502 & 69.347 \\
\hline The angle of the vein $(\mathrm{V})$ & 55.114 & 57.875 & 56.863 & 54.710 & 55.917 & 55.372 & 65.353 \\
\hline The angle of the kite base (BL) & 33.364 & 42.398 & 44.348 & 33.167 & 38.771 & 39.690 & 38.969 \\
\hline The angle of the kite apex (AL) & 44.886 & 53.993 & 45.350 & 46.043 & 46.731 & 49.222 & 44.494 \\
\hline
\end{tabular}

Note: SS is Slow Starter Clones, QS is Quick Starter Clones

Tabel 4. Means of the quantitative character of Hevea brasiliensis leaves from Quick Starter (QS) Clones type

\begin{tabular}{|c|c|c|c|c|c|c|c|}
\hline \multirow{2}{*}{ Quantitative character } & \multicolumn{7}{|c|}{ Clones of $\boldsymbol{H}$. brasiliensis plant from the entres collection plantation } \\
\hline & IRCA 19 & IRCA 101 & IRCA 130 & IRCA 230 & IRCA 317 & IRR 5 & IRR 220 \\
\hline Leaf length $(\mathrm{P})$ & 30.306 & 28.545 & 25.038 & 22.640 & 22.996 & 29.959 & 23.790 \\
\hline Leaf width (L) & 9.502 & 10.815 & 9.814 & 8.531 & 8.633 & 10.076 & 8.086 \\
\hline Left leaf strand of the vein $(\mathrm{HKr})$ & 4.752 & 5.403 & 4.907 & 4.297 & 4.317 & 5.038 & 4.029 \\
\hline Folding point of the leaf (TL) & 14.043 & 11.858 & 10.718 & 10.263 & 10.249 & 13.216 & 10.976 \\
\hline Center point of the leaf (TP) & 15.152 & 14.270 & 12.519 & 11.322 & 11.476 & 14.982 & 12.029 \\
\hline The angle of the natural base (B) & 68.977 & 75.091 & 62.409 & 65.450 & 65.064 & 62.992 & 54.691 \\
\hline The angle of the natural apex (A) & 58.159 & 80.466 & 82.161 & 72.688 & 73.598 & 59.984 & 66.122 \\
\hline The angle of the vein $(\mathrm{V})$ & 65.000 & 64.341 & 63.864 & 58.375 & 60.345 & 63.994 & 55.218 \\
\hline The angle of the kite base (BL) & 34.175 & 39.761 & 42.795 & 60.500 & 40.421 & 37.101 & 37.819 \\
\hline The angle of the kite apex (AL) & 38.734 & 50.091 & 48.722 & 46.650 & 49.851 & 43.485 & 42.763 \\
\hline
\end{tabular}

Tabel 5. Means of the quantitative character of Hevea brasiliensis leaves from Quick Starter (QS) and unidentified clones

\begin{tabular}{|c|c|c|c|c|c|c|c|}
\hline \multirow{3}{*}{ Quantitative character } & \multicolumn{7}{|c|}{ Clones of $\boldsymbol{H}$. brasiliensis plant from the entres collection plantation } \\
\hline & \multicolumn{4}{|c|}{ QS } & \multicolumn{3}{|c|}{ Unidentified clones type } \\
\hline & IRR 221 & PB 260 & PB 340 & RRIM 901 & IRCA 331 & IRCA 427 & IRCA 804 \\
\hline Leaf length $(\mathrm{P})$ & 23.231 & 29.116 & 30.517 & 22.521 & 24.874 & 22.563 & 25.782 \\
\hline Leaf width (L) & 8.933 & 10.989 & 11.339 & 8.820 & 8.244 & 8.882 & 8.839 \\
\hline Left leaf strand of the vein $(\mathrm{HKr})$ & 4.467 & 5.489 & 5.845 & 4.583 & 4.122 & 4.465 & 4.271 \\
\hline Folding point of the leaf (TL) & 11.354 & 13.753 & 13.941 & 9.652 & 11.125 & 10.566 & 12.568 \\
\hline Center point of the leaf (TP) & 11.616 & 14.551 & 15.367 & 11.318 & 12.421 & 11.290 & 13.063 \\
\hline The angle of the natural base (B) & 81.149 & 74.555 & 73.061 & 57.360 & 68.292 & 86.935 & 77.240 \\
\hline The angle of the natural apex (A) & 66.591 & 74.313 & 55.137 & 74.365 & 63.583 & 83.054 & 58.477 \\
\hline The angle of the vein $(\mathrm{V})$ & 59.623 & 57.942 & 56.842 & 55.188 & 57.988 & 68.791 & 62.094 \\
\hline The angle of the kite base (BL) & 44.718 & 44.576 & 41.066 & 40.411 & 35.052 & 44.783 & 42.470 \\
\hline The angle of the kite apex (AL) & 45.726 & 45.408 & 44.495 & 51.238 & 43.233 & 48.120 & 41.757 \\
\hline
\end{tabular}

Tabel 6. Means of the quantitative character of Hevea brasiliensis leaves from unidentified clones

\begin{tabular}{|c|c|c|c|c|c|c|}
\hline \multirow{2}{*}{ Quantitative character } & \multicolumn{6}{|c|}{ Clones of $\boldsymbol{H}$. brasiliensis plant from the entres collection plantation } \\
\hline & IRR 429 & IRR 440 & PC 10 & PM 10 & RRIM 908 & RRIM 2020 \\
\hline Leaf length $(\mathrm{P})$ & 23.895 & 19.222 & 32.100 & 30.134 & 29.579 & 22.538 \\
\hline Leaf width (L) & 8.682 & 7.406 & 11.029 & 11.600 & 12.548 & 8.603 \\
\hline Left leaf strand of the vein $(\mathrm{HKr})$ & 4.340 & 3.703 & 5.703 & 5.987 & 6.487 & 4.481 \\
\hline Folding point of the leaf (TL) & 11.128 & 8.448 & 14.536 & 14.036 & 13.399 & 9.835 \\
\hline Center point of the leaf (TP) & 11.947 & 9.560 & 16.154 & 15.088 & 15.019 & 11.556 \\
\hline The angle of the natural base (B) & 71.469 & 63.834 & 66.542 & 72.767 & 69.420 & 57.446 \\
\hline The angle of the natural apex (A) & 71.669 & 79.384 & 57.339 & 58.124 & 76.730 & 72.894 \\
\hline The angle of the vein $(\mathrm{V})$ & 62.040 & 58.350 & 54.750 & 56.321 & 55.550 & 56.570 \\
\hline The angle of the kite base (BL) & 40.987 & 40.882 & 35.994 & 43.267 & 44.716 & 38.712 \\
\hline The angle of the kite apex (AL) & 45.325 & 51.156 & 41.728 & 46.274 & 52.474 & 49.376 \\
\hline
\end{tabular}


Tabel 7. Large approximate of Hevea brasiliensis leaves

\begin{tabular}{lllllllll}
\hline Quantitative character & PB 217 & IRCA 18 & IRR 5 & PB 260 & PB 340 & PC 10 & PM 10 & RRIM 908 \\
\hline Leaf length (P) & 28.950 & 29.637 & 29.959 & 29.116 & 30.517 & 32.100 & 30.134 & 29.579 \\
Leaf width (L) & 10.803 & 10.431 & 10.076 & 10.989 & 11.339 & 11.029 & 11.600 & 12.548 \\
Large (cm2) & 312.732 & 309.133 & 301.865 & 319.973 & 346.045 & 354.045 & 349.538 & 371.160 \\
\hline
\end{tabular}
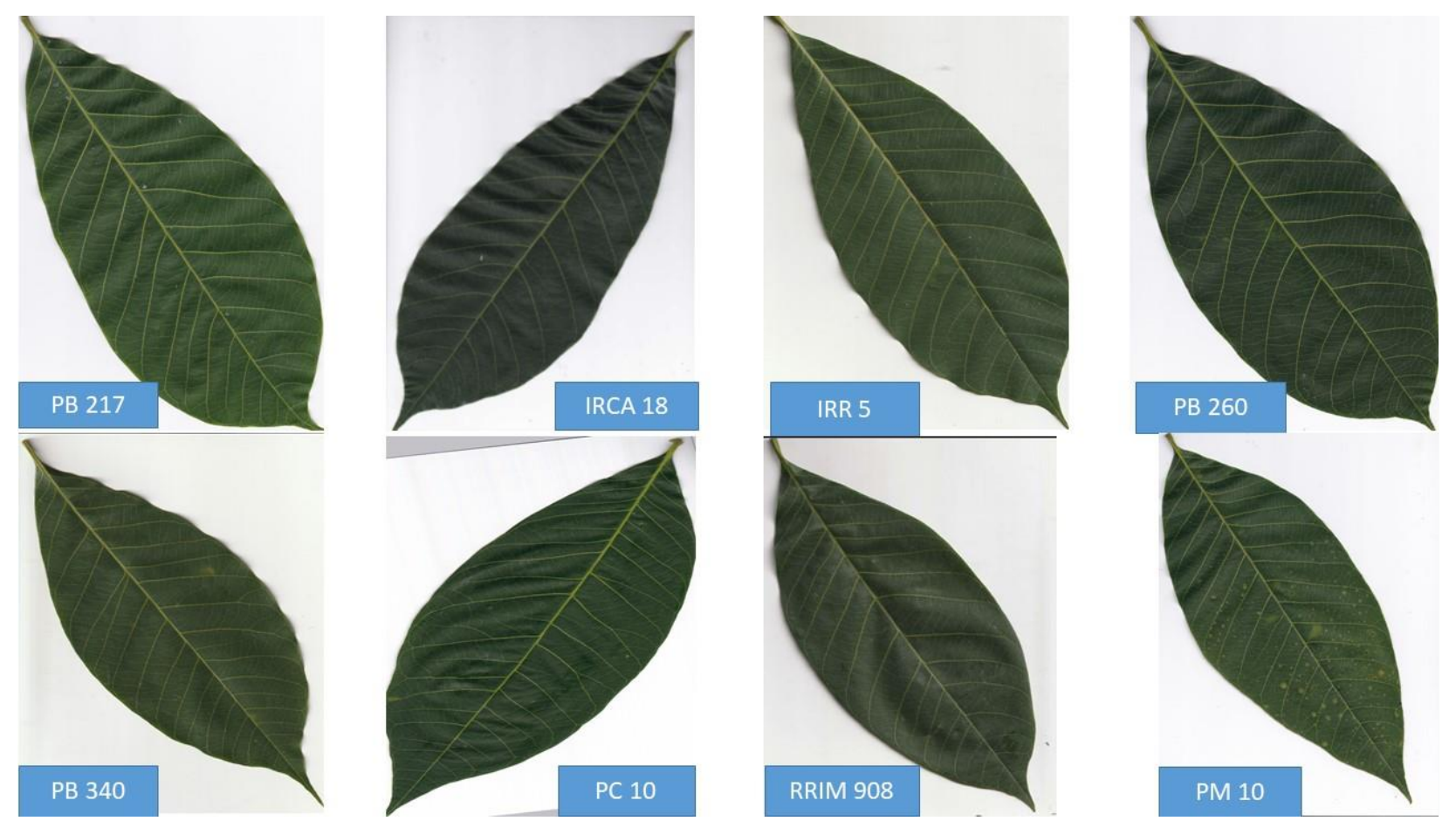

Figure 2. Hevea brasiliensis leaves sample. Eight leaves from Table 7 to be represented to some of the clones, PB 217, IRCA 18, IRR 5, PB 260, PB 340, PC 10, RRIM 908, and PM 10

\section{Discussion}

Clones identification is a necessary component of most studies of biological diversity, and computational approaches are beginning to automate it. The influence of the interaction of clones with quantitative characters measured emphasizes that this is very capable of being a character of $H$. brasiliensis clones, this was proven by Table 2 the annova procedure from the probability value of $\mathrm{K}$ as clones, $\mathrm{C}$ as a quantitative character, and both interaction $(<0.0001)$. Similar research was also conducted to identify weeds by introducing a plant species based on the shape and arrangement of its leaf bones by moment invariant method (characteristic of weed leaf shape and image) and lacunarity (texture feature of weed image) (Herman and Harjoko 2015).

The importance of the role of leaf detection and classification (Thyagharajan and Raji 2018) for agriculture, forestry, rural medicine, and other commercial applications. Diagnosis of plant leaf disease for automatic identification is highly demanded on precision agriculture (Ahmad et al. 2018; Bakhshipour et al. 2017); Environment and Forestry need solutions for automatic tree species identification (Bakhshipour et al. 2017) rural medicine
(Ahmad et al. 2018) involves the recognition of plant species to decide the suitability of consumption. Other research $H$. brasiliensis tree leaves are naturally in palmate leaf class, as trifoliate leaves where there are 3 leaves on each petiole that join in their base. Thus reflecting the position information of the leaves whether the leaves overlap or separate. Therefore, this unique feature can be used to distinguish certain leaves from clones of others to identify tree types. This research was conducted by Tekkesinoglu et al. (2014) on the problem of identifying overlapping leaves against a complex background. The approach taken to identify $H$. brasiliensis leaf boundaries based on morphological operations and edge detection methods shows promising results.

Generally for plants, the leaves play a very important role as the center of metabolism in breaking down nutrients from the soil which are transported by the xylem vessels at the roots to the leaves and processed into photosynthate to be circulated to all parts of the plant by phloem vessels as energy for growth. Likewise for $H$. brasiliensis plants, the production of latex which is the main goal of $H$. brasiliensis cultivation in plantations, determined by leaves. In this research, a number of clones used as sample 
sources refer to previous work (Pratomo et al. 2020) of detecting polyisoprenoid in $H$. brasiliensis clones, which have defined the types of clones based on the types of quick starter and slow starter clones (Herlinawati and Kuswanhadi 2013; Martiansyah et al. 2018; Obouayeba et al. 2010; Woelan et al. 2012). And some pictures of leaves showed in Figure 2. The importance of identifying clones is carried out since the beginning of the selection of parent clones for the artificial crossing to be known with certainty the male elders and their female elders (Pasaribu and Suhendry 2018).

$H$. brasiliensis leaves also described the stress response of plant drought and tolerance complex biological process. The results showed that the relative water content (RWC) in the leaves continues to decrease with the severity of drought stress. Wilted leaves are observed for 7 days without water (dww). H. brasiliensis tree clone GT1 leaf sample (original clone breed in Indonesia). These results (Wang and Li-feng 2014) suggest that drought stress adaptation in $H$. brasiliensis trees is regulated by energy biosynthesis, antioxidative enzymes, and osmoregulation. With regard to the influence of weather and climate, the results of research (Liyanage et al. 2018) in China showed that two clones of RRIM 600 and GT1 (who are also familiar in Indonesia) were defoliated during the last week of December and refoliated in the last week of January. This helps $H$. brasiliensis growers to schedule appropriate disease control measures, as well as design hybridization programs aimed at the production of clones resistant to foliar disease. Recently, it has been reported that the tolerance level of the GT1 seedlings to drought with the addition of PEG 6000 by showing an increase of taproot length (Pasaribu et al. 2021).

Visually, although only from the length and width of the leaves, it can be seen that the differences in each clone were observed and their characters were measured. And for the details, measurements were taken digitally. Figure 2 is related to Table 6 describing different large approximate of $H$. brasiliensis leaves. The results of Suhendry and Pasaribu (2009) showed that H. brasiliensis leaves have specific quantitative characteristics among clones so that the characteristics contained in the leaves can be used as a description in identifying an $H$. brasiliensis clone. Variations in leaf size and length, leaf area, the ratio of leaf length and width, the proportion of character length and width of leaves, corners of leaves, and proportions of leaf angles and conversion values differ very manifestly delivered by clones thus emphasizing the character in identifying $H$. brasiliensis clones.

In digital techniques, before the leaves were measured first done the separation of the background through cropping techniques. The cropping technique was performed visually by using the magic tool in the Adobe Photoshop Software program. Pasaribu and Suhendry (2018) have reported the influence of operator accuracy level did not cause different phenomena between clones. This is evidence from the fact the interaction of methods with clones. The interaction of identification techniques with clones indicated that the technique of measuring $H$. brasiliensis leaf characteristics were not influenced by clones, meaning that any clone can be measured by digital identification techniques as carried out in this study.

In conclusion, the identification method digitally on the characterization of $H$. brasiliensis leaves showing that the characteristics contained in $H$. brasiliensis leaves were very suitable and used as the first character in identifying an $H$. brasiliensis clone.

\section{ACKNOWLEDGMENTS}

This study was supported by the Penelitian Disertasi Doktor project No. 11/AMD/E1/KP.PTNB/2020, from Directorate General of Research and Community Service, the Ministry of Research and Technology/National Agency for Research and Innovation of the Republic of Indonesia.

\section{REFERENCES}

Agus S, Putra IKGD, Wirdiani NKA. 2015. Herbs recognition based on android using opencv. Intl J Image Grap Signal Process 7 (2): 1-7.

Ahmad J, Muhammad K, Ahmad I, Ahmad W, Smith M. 2018. Visual features-based boosted classification of weeds for real-time selective herbicide sprayer systems. Comput Ind 98: 23-33.

Bakhshipour A, Jafari A. 2018. Evaluation of support vector machine and artificial neural networks in weed detection using shape features. Comput Electron Agric 145: 153-160.

Bakhshipour A, Jafari A, Nassiri SM, Zare D. 2017. Weed segmentation using texture features extracted from wavelet sub-images. Biosys Eng 157: $1-12$.

Bhardwaj A, Kaur M, Kumar A. 2013. Recognition of plants by leaf image using moment invariant and texture analysis. Intl J Innov Appl Studies 3 (1): 237-248.

Bruno OM, Plotze RO, Falvo M, Castro M. 2008. Fractal dimension applied to plant identification. Inf Sci 178 (12): 2722-2733.

Casanova D, de Mesquita JJ, Bruno OM. 2012. Plant leaf identification using Gabor wavelets. Intl J Imag Syst Technol 9: 236-243.

Cerutti G, Laure T, Julien M, Antoine V, Didier C. 2013. Understanding leaves in natural images - A model-based approach for tree species identification. Comput Vis Image Understanding 117 (10): 14821501. doi:10.1016/j.cviu.2013.07.003

Ghasab MA, Khamis S, Mohammad F, Fariman HJ. 2015. Feature decision making ant colony optimization system for an automated recognition of plant species. Expert Syst Appl 42 (5): 2361-2370.

Goyal N, Kumar N. 2018. Plant species identification using leaf image retrieval: a study. Int Conf Comput, Power Commun Technol 405411.

Hidayat T, Nilawati AR. 2018. Identification of plant types by leaf textures based on the backpropagation neural network. Int J Electric Comput Eng 8 (6): 5389-5398.

Herlinawati E, Kuswanhadi. 2013. Metabolic activity of several $H$. brasiliensis clones at different tapping frequencies and stimulation. $\mathrm{J}$ Rubb Res 31: 110-116.

Herman, Harjoko A. 2015. Introduction of weed species based on the shape and texture of leaves using artificial neural networks. Indones J Comput Cybern Syst 9 (2): 207-218. DOI: 10.22146/ijccs.7549.

Kadir A, Nugroho LE, Susanto A, Santosa PI. 2012. Experiments of Zernike moments for leaf identification. J Theor Appl Inform Technol 41 (1): 82-93.

Kaur S, Kaur P. 2019. Plant species identification based on plant leaf using computer vision and machine learning techniques. J Multimedia Inform Syst 6 (2): 49-60. doi:10.33851/JMIS.2019.6.2.49.

Kolivand H, Fern BM, Rahim MS, Sulong G, Baker T, Tully D, Niedz RP. 2018. An expert botanical feature extraction technique based on phenetic features for identifying plant species. PLoS One 13 (2): 0191447. doi:10.1371/journal.pone.0191447.

Lee KB, Hong KS. 2013. An implementation of leaf recognition system using leaf vein and shape. Int J Bio-Sci Bio-Technol 5 (2): 57-66. 
Liyanage KK, Khan S, Ranjitkar S, Yu H, Xu J, Brooks S, Beckschäfer P, Hyde KD. 2018. Evaluation of key meteorological determinants of wintering and flowering patterns of five $H$. brasiliensis clones in Xishuangbanna, Yunnan, China. Intl J Biometeorol 63 (5): 617-625. doi:10.1007/s00484-018-1598-z

Martiansyah I, Putranto RA, Khumaida N. 2018. Sucrose analysis in leaf tissue of two contrasted $H$. brasiliensis tree clones under abiotic and biotic stresses. IOP Conf: Earth Environ Sci 183 (1): 012018.

Obouayeba S, Soumahin EF, Coulibaly LF. 2010. Low intensity tapping systems applied to clone PR 107 of Hevea brasiliensis (Muell. Arg.) in South-eastern Côte d'Ivoire: Influence of the nature of the exploited bark and the position of tapping panel. Agric Biol J North Amer 1: 1106-1118.

Pasaribu SA, Basyuni M, Purba E, Hasanah Y. 2021. Drought tolerance selection of GT1 rubber seedlings with the addition of polyethylene glycol (PEG) 6000. Biodiversitas 22 (1): 394-400

Pasaribu SA, Suhendry I. 2018. Identify H. brasiliensis clones based on variations in leaf characteristics. H. brasiliensis Res J 36 (1): 37-50.

Pallavi VS, Devi V. 2014. Leaf recognition based on feature extraction and Zernike moments. Int J Innovative Res Comput Comm Eng 2 (2): 67-73.

Pratomo B, Lisnawita, Nisa TC, Basyuni M. 2020. Detection of polyisoprenoid composition in quick starter and slow starter clones of Hevea brasiliensis. Int J Agric Biol 20 (9): 1098-1106.

Suhendry I, Pasaribu SA. 2009. Identify H. brasiliensis clones through leaf characteristics. 1. Variation in leaf size. H. brasiliensis. Res J 27 (1): $1-20$.
Tekkesinoglu S, Shafry MR, Rehman A, Ismail MA, Tanzila S. 2014 Hevea leaves boundary identification based on morphological transformation and edge detection features. Res J App Sci Eng Tech 7 (12): 2447-2451.

Thyagharajan KK, Raji KI. 2018. A review of visual descriptors and classification techniques used in leaf species identification. Arch Comput Method Eng 26 (4): 933-960.

Thibaut B, James SC, Paolo R, Sarah B. 2011. Shape and texture-based plant leaf classification. International Conference on Advanced Concepts for Intelligent Vision Systems. Springer, Berlin, Heidelberg, 2010.

Trishen M, Ramsurn M, Kishnah S, Pudaruth S. 2015. Plant leaf recognition using shape features and colour histogram with k-nearest neighbour classifier. Procedia Comput Sci 58: 740-747.

Valliammal N, Geethalakshmi SN. 2012. Plant leaf segmentation using non linear K means clustering. Intl J Comput Sci Issues 9 (3): 212.

Wang, LF. 2014. Physiological and molecular responses to drought stress in H. brasiliensis tree (Hevea brasiliensis Muell. Arg.). Plant Physiol Biochem 83: 243-249. DOI: 10.1016/j.plaphy.2014.08.012

Wirdiani NKA, Sudana OAAK. 2016. Medicinal plant recognition of leaf shape using localized arc pattern method. Intl J England Technol 8 (4): 1847-1854.

Woelan S, Junaidi, Syarifah AP. 2012. Optimizing yield IRR 200 series using some tapping systems in plot promotion trial. Jurnal Penelitian Karet 30: 75-85. [Indonesian] 